\title{
Balance de la acreditación universitaria en el Perú
}

\author{
University accreditation's balance in Perú
}

La acreditación en el país todavía no se implanta tal cual debe funcionar. El Perú está entre los países que recientemente están entrando a los procesos de acreditación y en relación con Latinoamérica estamos rezagados. Pero el hecho es que el Consejo de Evaluación, Acreditación y Certificación de la Calidad de la Educación Superior Universitaria (CONEAU) ya tiene sus reglamentos, sus indicadores; tiene lo que sería los materiales administrativos, legales, para emprender este proceso y a la fecha ya ha hecho la convocatoria para algunas carreras como salud, educación, biología, psicología, todas las medicinas y todo lo que es el área de salud

Naturalmente, la acreditación que está funcionando en el Perú corresponde a una fase inicial, una fase que faltaría, por ejemplo, que se establezcan las acreditadoras para que el trabajo de acreditación no esté a cargo de un mismo órgano, que es un órgano de la administración pública y que de alguna forma tiene injerencia el Estado. La teoría indica que los evaluadores deben ser organismos independientes del Estado, altamente tecnificados y especializados, que basándose en su prestigio tienen que hacer un trabajo de evaluación completamente imparcial.

Así, en teoría, está bien que exista el CONEAU, este debe dar las pautas, los documentos; pero quienes hacen el trabajo de evaluación, que funcionan como pares, los pares externos, generalmente son otros organismos, organismos especializados, si quieren le llamamos "agencias de evaluación", que prestan ese servicio de manera exclusiva, concluyen el trabajo y le entregan los resultados al CONEAU.

La acreditación en el Perú ha comenzado con las facultades de Medicina y se llegó a acreditar por un período máximo de cinco años. Entonces, hay facultades de Medicina que tienen esa acreditación, la acreditación nacional. Hay universidades que se adelantaron a ese proceso, como la Católica, Cayetano Heredia, Lima y parece que también la Pacífico.

Sin embargo, la acreditación que se está realizando en el país es por carreras, es parcial, creo que ninguna universidad ha llegado a una acreditación total y plena. Me parece que San Marcos se ha acreditado institucionalmente, pero cuando se acreditan de este modo, no significa que están acreditando todas las carreras que tenga la universidad, sino, si se quiere

1 Rector de la Universidad Ricardo Palma; ex presidente de la Asamblea Nacional de Rectores, Perú.

(*) Artículo redactado a partir de la entrevista al Dr. Iván Rodriguez realizada por el Prof. Víctor Campos Urbano en la ciudad de Lima, 2012. 
decir, son los servicios, la calidad de los servicios que presta la universidad, desde la administración central. Entonces, son procedimientos que van a ser examinados, como por ejemplo el de admisión. Y es que también la acreditación va por procesos, como por decir, la graduación, vamos a acreditar la graduación. De manera que sería todo el sistema de graduación que entraría en la acreditación.

La Universidad Ricardo Palma, por ejemplo, tiene Medicina acreditada con el sistema nacional, pero también internacionalmente, que es lo que han hecho algunas universidades. Las universidades que tienen acreditación por facultades han recurrido a evaluadoras externas, ya sea de Colombia, Argentina, México, Estados Unidos o Canadá.

$Y$ es que se está aprendiendo, todos estamos aprendiendo, están aprendiendo las universidades, está aprendiendo también el órgano acreditador, porque esto ya tiene bastante tiempo en el primer mundo. En lo que concierne a América Latina, México, Argentina, son los países que han comenzado, después Colombia. Estos son los que más experiencia tienen. De tal manera que en conjunto estamos aprendiendo. La mayoría de universidades está en lo que se llama autoevaluación, para que identifiquen sus debilidades, sus fortalezas, y de acuerdo con ello vayan elaborando su plan de mejora continua, y una vez que hayan hecho eso, recién pueden entrar a la evaluación externa por los pares. Ahora, ¿̇qué trabajo se ha estado haciendo con cierta intensidad? El que corresponde a crear la mentalidad de la evaluación y la mentalidad de lo que se llama cultura de calidad, porque la acreditación existe para certificar la calidad.

Como expresaba, aquí solamente tenemos el CONEAU, y queremos que este haga todo, incluso el trabajo de evaluación. Pero lo que existe como proceso ya desarrollado, maduro, es que el órgano CONEAU, o el nombre que tenga en el país, generalmente no hace la evaluación de modo directo, sino a través de acreditadoras, que son organizaciones privadas, altamente especializadas, que tienen profesionales preparados y simplemente intervienen solo para hacer la evaluación: hacen la evaluación, emiten su informe, le entregan al CONEAU, y este es el que da el certificado. Entonces, en el Perú falta la instalación de las acreditadoras que son las que van a trabajar conjuntamente con el CONEAU. Ahora, este órgano tiene a su cargo y remunera a los evaluadores, y son ellos los que van hacer las visitas a las universidades. Pero reitero, esa parte de la evaluación misma, generalmente no la asume el órgano, que en el caso del Perú es CONEAU, sino son organizaciones privadas que no tienen conexión con el Estado.

Si algo han avanzado las acreditadoras privadas internacionales tiene que ser por la experiencia. ¿̇uál es el riesgo cuando el órgano oficial es el que evalúa? El riesgo es de la infiltración política. Si los gobiernos tienen el poder de movilizar eso, entonces pueden dirigir la acreditación a favor o en contra de una universidad, porque esa universidad podría no ser favorable a un determinado gobierno.

Pero no solo estoy de acuerdo que haya acreditadoras internacionales, también pueden haber peruanas, lo que se quiere es que se organicen como tales, no ser dependencias de la administración pública, sino que tengan que ser organizaciones privadas, altamente técnicas, sin conexión con el Estado.

Respecto a la Superintendencia de Universidades, no estoy de acuerdo porque eso puede funcionar para la parte económica, comercial; pero no para meterse con las universidades. El CONEAU está bien que exista, es el órgano que da las políticas, el órgano con toda la investidura oficial; lo que digo es que en el mundo va a existir al lado de ese órgano, acreditadoras privadas que van hacer el trabajo de la evaluación, porque en este trabajo es que pueden presentarse las dificultades si es que hubiera una contaminación política en el proceso. 


\section{Proceso de gran movilización}

Incluir el tema de la acreditación como una política de Estado dentro del Acuerdo Nacional, le puede dar seriedad, responsabilidad, pero todo tiene que ser dentro del espíritu de la acreditación. La acreditación es un proceso que nunca se da de forma automática. Que la universidad presente sus documentos, que vengan los evaluadores y digan que ya todo está bien e inmediatamente le otorguen la certificación, eso no es así, porque generalmente van a formular observaciones, recomendaciones; y si formulan observaciones, tienen que regresar a verificar si se cumplieron o no, si se levantaron las observaciones, si cumplieron o no las recomendaciones. Entonces, estos son procesos que aún ni siquiera se pueden decir que van a durar un año o dos, no se sabe, depende de la situación o punto de partida de las universidades.

Debo decir algo más, la acreditación también significa una inversión, significa presupuesto, porque si por ejemplo yo tengo la universidad de determinada manera, llamo a la acreditación, vienen los acreditadores y me dicen: "Oiga usted, acá le faltan equipos"; tengo que comprar, pues, eso sería una observación. "Usted tiene la Facultad de Medicina, pero no tiene un laboratorio de simulación", me observan; entonces, no puedo llamar a los evaluadores para decirles: "Han pasado seis meses y yo todavía no tengo dinero, no puedo comprar, no puedo hacer el laboratorio de simulación; entonces, espérenme o denme el certificado, yo les firmo un documento de compromiso"; eso no va a ocurrir, se tiene que levantar las observaciones. Pero todo este proceso significa una inversión, por eso es que las universidades nacionales están en dificultades, porque tienen presupuestos muy reducidos y no tienen para hacer frente a una inversión yo diría abierta, de monto abierto, para reunir todos los requisitos infraestructurales y de otra naturaleza que puedan responder a los requerimientos de los indicadores de la calidad.

El proceso de acreditación comprende infraestructura, procedimientos. Por ejemplo, un laboratorio tiene que presentar guías de práctica y no solo decir: "Tengo acá una sala con 15 microscopios para 15 alumnos"; eso no es suficiente. Se debe tener no solo todos los insumos, sino todo el programa de prácticas, todas sus guías, qué hace el profesor, qué hacen los alumnos, el tiempo, si va a la biblioteca. No es un asunto simple, sino cada aspecto implica toda una ramificación de asuntos adicionales.

Igual es con los estudiantes y egresados. Van a hacer reuniones con ellos, van a estudiar la colocación del egresado, qué índice de colocación en el mercado laboral tienen. Hay que citar a los egresados, hay que estar haciendo un empadronamiento. Van a haber otras fuentes, no solo hacen sondeos de opinión en la sociedad, en la comunidad sobre el prestigio; hay que presentarles todo lo que haya, por ejemplo, periódicos, revistas. Es decir, es un proceso en el cual la universidad tiene que demostrar cuáles son sus logros institucionales; y no qué logró durante el año, sino en toda su existencia. Es complicado, exige que trabaje todo un grupo estas condiciones de calidad, que se nombren, y los profesores que tienen esta función deben desempeñarla en una forma completamente responsable y así, de actividad intensa, y no decir: "Eso lo dejo y no lo puedo hacer hasta el próximo lunes". Este proceso es un trabajo de todos los días.

Sobre la preocupación de cómo enfrentar el proceso de acreditación en la universidad pervana con estudiantes que por lo general están por debajo del promedio en comprensión de lectura y razonamiento matemático, considero que los indicadores están adecuados a la realidad pervana, no se aplican indicadores de EE.UU, ni de Alemania ni de Francia. Por eso, el órgano que se cree en el Perú tiene que trabajar a partir de la realidad peruana. Por ello se dice que son indicadores mínimos, no máximos. La universidad para recibir la acreditación tiene que cumplir y cubrir los indicadores en su nivel mínimo; si va más allá de lo mínimo, es mejor. Son procesos que necesitan dedicación de personal, una movilización de una serie de factores. 
Desarrollar el proceso de acreditación universitaria sin la acreditación previa de los colegios, que es otra de las preocupaciones, sí es posible. En la secundaria, en la básica, recién están igual. Si en la universidad recién comenzamos, en la básica sucede lo mismo. Ahora, la superación de todas estas debilidades es asunto de que el Estado asuma las medidas correctivas, pero eso implica inversión, y estamos viendo que los presupuestos de educación siguen siendo los que menos recursos reciben. Tiene que mejorarse el magisterio, eso tampoco está ocurriendo; y no solo en la formación profesional, sino también darles becas, mandarles al exterior para uno, dos años de estudios. Bueno, nada de eso tenemos. Indudablemente que la acreditación sí puede funcionar, pero será mejor cuando todo el sistema educativo también tenga mayores niveles de calidad. Ahí será mucho mejor, pero sí puede funcionar y de hecho está funcionando.

Respecto a la voluntad política del actual Gobierno hacia la universidad en este proceso de acreditación, me parece que no existe, creo que está en la misma línea de los gobiernos anteriores, que si hacen algo, hacen apenas y parcialmente, cuando aquí se necesita una dedicación de recursos bastante fuertes, porque la mayoría de problemas vienen desde un desnivel. Las universidades en el Perú no tienen lo que deben tener y generalmente es infraestructura, equipamiento, bibliotecas, y todo eso implica una inversión.

Yo creo, por ello, que este proceso tiene que ser agilizado e intensificado ya por cada universidad. Ya no el Estado, el Gobierno, sino cada universidad debe hacer sus programas y ver cómo en buena forma obtiene sus recursos para cubrir las necesidades o requerimientos.

\section{Acreditación con autonomía real}

Frente a la suspensión temporal de la creación de más universidades hasta la vigencia de la nueva Ley Universitaria, yo pienso que se tiene que suspender no menos de diez años, con tres años no se hará nada, es como que no suspendemos absolutamente nada. Pero tiene que ser la suspensión para el Estado y los particulares, no solo para los últimos. El desorden lo hacen unos y otros, el Estado y los particulares. La falta de calidad está en uno y otro lado. Si queremos ordenar, tiene que haber una suspensión de creación de universidades por ambas partes, no menos de diez años, y paralelamente fortalecer los sistemas de acreditación, para que sea el propio sistema, con todas las prerrogativas y plazos, el que determine qué universidad subsiste y qué universidad pueda verdaderamente garantizar una formación de calidad.

Pese a ello, considero que no hay tanta necesidad de una nueva Ley Universitaria, con la actual norma se puede trabajar. Lo que han creado es una idea de esa naturaleza porque es fundamentalmente electoral, lo que quieren es descabezar a las universidades para que aparezcan nuevos gobiernos universitarios; pero eso desestabilizará a las universidades, es frustrarle sus proyectos. No es la mejor medida. Entre los proyectos de ley están: que se disuelvan los órganos de gobierno en las universidades, se cesen a las autoridades, se abra proceso electoral, con la idea de que en un mismo día en todo el Perú se instalen todos los rectores. Es una locura, pues, que haya elecciones en las 130 universidades. Es simple y llanamente ideas de gente que no conoce qué es una universidad y no tienen la idea de lo que significa que haya, simultáneamente, procesos de elecciones de autoridades universitarias en todas las universidades del Perú. No tienen la menor idea del problema social que estarían creando.

Lo que se debe hacer es respetar la autonomía y hacer que esta sea un atributo esencial, real y efectivo en la universidad, no tener una autonomía nominal, una autonomía solo de palabra. Entonces, dejar en libertad a las universidades para que se organicen, para que determinen su designación de autoridades; eso es lo que deberían hacer, no tenerlas a todas 
encamisetadas, maniatadas. Ahí estaría el remedio, simplemente decir hay que dejar en libertad a las universidades y fiscalizarlas; es decir, compensar esa libertad con la fiscalización, con la exigencia de la rendición de cuentas, de buenas cuentas, de las autoridades universitarias, con todas las responsabilidades legales, económicas, morales, porque así tiene que ser, y autoridad que no usa bien los recursos de la universidad, malgasta, lapida, derrocha, se apropia; bueno, no quedaría otra alternativa que sus procesos penales y sus sanciones debidas.

No puede haber impunidad en el país en ninguna área, menos en la educación. Hay gente de muy buena calidad moral, profesional, académica, hay gente que tiene muchas ideas y que puede hacer muchas cosas; pero se va a ver trabada, dificultada, con una política de desconfianza, de freno, que tienen todas las universidades. Entonces, lo mejor que puede haber es dejarlas en libertad y fiscalizarlas, no para que se degenere esa libertad, sino para que la misma sea bien usada.

La autonomía pone a la universidad, para este desempeño, bajo fiscalización del Congreso de la República. La autonomía significa eso, que no está bajo dependencia del Ejecutivo sino del Legislativo, y se pueden crear, como sucede en el mundo, los órganos suprauniversitarios, como en el país es la Asamblea Nacional de Rectores.

En casi todo lugar existe la Asamblea de Rectores y el Ministerio de Educación Superior. Hay que reivindicar, entonces, la autonomía universitaria. 